\title{
Psychological Outlook of Cinema
}

\author{
Nandha Kumara Pujam, Geo. A. Joseph ${ }^{2}$, Deyashini Lahiri ${ }^{3}$, Amrit Pattojoshi ${ }^{4}$ \\ ${ }^{1}$ Department of Clinical Psychology, SRM Medical College Hospital and Research Center, \\ Potheri, Kanchipuram, ${ }^{3}$ Assistant Professor, Department of Clinical Psychology, \\ Central Institute of Psychiatry, Ranchi, ${ }^{4}$ Hitech Medical College, Bhubaneswar
}

\section{INTRODUCTION}

Movies transcend all barriers and differences, whether these barriers are culture, language, religion, geographic borders, or belief systems. In contrast to language which is a way of communicating thoughts and feelings, and it is a system that has particular rules, signs, and symbols that shape it and make it meaningful, similar rules are found in movies; however, movies are not localized to one country or group of people. Therefore, movies are a commentary on more than society; they inform us about the human condition. The images projected in cinema allow individuals to look into the working of another family through a story line that lets them forget their own worries for a while. Films encourage people to look at events in a fresh manner, suggest possible solutions to their problems, and confirm their views and, perhaps, prejudices. Besides fun and entertainment going to cinema may reflect a desire to pry into other people's lives and get the vicarious pleasure of gossiping without really losing anything of one's own. People may get relaxed while watching movies by feeling that their problems are not as bad as those of the people on the screen (Bhugra, 2006).

Film relies on the mental state of the viewers each viewer may take home the same or different message after watching the film once or several times. A key factor in cinema's contribution to society is the immense possibilities it holds for disseminating good or evil, given its widespread influence on the juvenile as well as the adult mind (Bhugra, 2006).

\section{Corresponding Author :}

Nandha Kumara Pujam, Assistant Professor, Department of Clinical Psychology, SRM Medical College Hospital and Research Center, Potheri, Kanchipuram, 603203.

\section{WHAT IS CINEMA?}

The word cinema emerged from Greek root word kinēma which means"movement". The French term cinéma, was originally coined by the Lumière brothers in 1890s by shortening the word cinématographe, which literally means "movement writing" (www.encarta.msn.com). Cinema is an Art because it is something wrought and constructed by a person (or group of people) that has no specific practical function; only to explore, engage, inform, entertain and edify. Likewise, cinema is a 'moving image' because this simple phrase alone sets cinema apart from its parents i.e. theatre, photography and architecture.

\section{BRIEF HISTORY OF CINEMA}

Formal history of cinema starts with Dickson; in 1891 with the direction of Thomas Alva Edison he made a cinema apparatus known as Kinetograph. He displayed it in public on 1893, using the viewing apparatus called the Kinetoscope. Later the Lumière brothers, Louis and Auguste, made first successful projector known as Cinématographe with this they gave the first show in 1895. By 1903 Smith produced a system of colour cinematography called Kinemacolor that was quite successful up to World War.

During World War I, the film industries in the various European countries were badly damaged. The economic depression of the 1930s severely reduced cinema income up to 1933, the major technical development of 1934 was the first realization of a successful system of full-colour cinematographyTechnicolor. 


\section{Psychological Outlook of Cinema}

During World War II film production decreased somewhat, but cinema-going greatly increased, as did profits.

During the mid-1970s, more pornographic theatres called "adult cinemas" were established, and the legal production of pornographic films began. The porn cinemas finally died out during the 1980s, when the popularization of the home VCR and pornography videotapes allowed audiences to watch these films at home. During 1995 computer animation would grow to become the dominant technique for feature length animation. As of 2010, 3D movies are gaining increasing popularity (Microsoft Encarta Encyclopedia, 2001).

\section{MAJOR CLASSIFICATIONS OF (CINEMA) FILMS}

\section{ACTION FILMS}

Action films usually include high energy, bigbudget, physical stunts and chases, possibly with rescues, battles, fights, escapes, destructive crises (floods, explosions, natural disasters, fires, etc.), non-stop motion, spectacular rhythm and pacing, and adventurous, often two-dimensional 'good-guy' heroes (or recently, heroines) battling 'bad guys'. Includes the James Bond 'fantasy' spy/espionage series, martial arts films, a major sub-type is the disaster film.

\section{COMEDIES}

Various forms of comedy can be found throughout cinematic history, including slapstick, screwball, spoofs and parodies, romantic comedies, black comedy (dark satirical comedy) etc.

\section{CRIME AND GANGSTER FILMS}

Crime (gangster) films are developed around the sinister actions of criminals or mobsters, particularly bank robbers, underworld figures, or ruthless hoodlums who operate outside the law, stealing and murdering their way through life. Criminal and gangster films are often categorized as film noir or detective-mystery films - because of underlying similarities between these cinematic forms. This category includes a description of various 'serial killer' films.

\section{DRAMATIC FILMS}

Dramatic films are serious, plot-driven presentations, portraying realisticcharacters, settings, lifesituations, and stories involving intense character development and interaction. Usually, they are not focused on special-effects, comedy, or action. Dramatic films are probably the largest film classifications, with many subsets. Dramatic biographical films (or "biopics") are major sub-types, as are 'adult' films (with mature subject content).

\section{EPICS/HISTORICAL}

Epics include costume dramas, historical dramas, war films, medieval romps, or 'period pictures' that often cover a large expanse of time set against a vast, panoramic backdrop. Epics are often a more spectacular, lavish version of a biopic film. Some 'sword and sandal' films (Biblical epics or films occurring during antiquity) qualify as a subcategory.

\section{HORROR FILMS}

Horror films are designed to frighten and to invoke our hidden worst fears, often in a terrifying, shocking finale, while captivating and entertaining us at the same time in a cathartic experience. There are many sub-types of horror: slasher, teen terror, serial killers, satanic, Dracula, Frankenstein, etc.

\section{MUSICAL/DANCE}

Musical/dance films are cinematic forms that emphasize full-scale scores or song and dance routines in a significant way (usually with a musical or dance performance integrated as part of the film narrative), or they are films that are centered on combinations of music, dance, song or choreography. Major subtypes include the musical comedy or the concert film. 


\section{Psychological Outlook of Cinema}

\section{WAR FILMS}

War (and anti-war) films acknowledge the horror and heartbreak of war, letting the actual combat fighting on land, sea, or in the air provide the primary plot or background for the action of the film. War films are often paired with other categories, such as action, adventure, drama, romance, comedy (black), suspense, and even epics and westerns, and they often take a denunciatory approach toward warfare. They may include stories of military operations, and training. (Tim, 2010).

\section{OTHER MAJOR FILM CATEGORIES}

Animated films are often considered kids or familyoriented films, although they may be enjoyed by all ages.

Children films are specifically designed for children of 12 years or below which do not include topics or scenes with violence, foul language or religious issues and cover a wide range of categories such as comedy, adventure, fantasy, musicals, etc.

Sexual/Erotic films that focus on themes with either suggestive, erotic or sensual scenes or subjects, sometimes with depictions of human nudity and lovemaking, but not always of an extremely explicit in nature.

Silent films are films that have no synchronized soundtrack and no spoken dialogues, without dialogue featured titles for dialogue segments, and often were accompanied by live music (Tim, 2010).

\section{CINEMA AS A THERAPEUTIC TOOL}

Newton (1995) mentioned that cinematherapy makes processing the unconscious material accessible more easily as well as reducing resistance because it is indirect. It gives greater insight to patients about their dilemmas or personalities, and creates useful metaphors for patients' problems (Berg-Cross, Jennings \& Baruch, 1990; Calisch, 2001). Furthermore,
Berg-Cross et al. (1990) argued that cinematherapy helps building the therapeutic alliance by bonding therapist's empathy and reducing client's fear about therapy. By prescribing an individual or family the task of viewing film, clinicians anticipate that clients will connect their own life experiences with those demonstrated on the screen, and ultimately obtain new solutions to old problems(Hesley, 2000).

\section{DISCUSSION}

Cinema from the perspective of identity, culture and socio economic factors

Socially and emotionally, individual identifies oneself in the cinema with the projected character in the movie. The Surnames indicates the actor caste, in order to avoid this discrimination, surnames was avoided by many actor for example Manoj Kumar never used his surname (Goswami), so the character will be a national identity but some emphasized their identity and caste like Manoj Bajpai used his surname. Heroes in the 1950s and 1960s also used the same name, whichever character they played. For example, Guru Dutt played Vijay several times, as did Amitabh Bachchan subsequently. Salman khan was called Prem and Shah Rukh Khan was Raj in several films (Bhugra, 2008). In the last quarter of the twentieth century, erotic scenes were shown indirectly through images of say, two flowers entwined, waves breaking on the shore, or a train entering a tunnel. However, there has been a distinct change, in the film hum Amitabh Bachchan could sing, Jumma, Chumma de de (kiss me) and the heroine in Khalnayak could be asked, what is under your blouse? Reflects the social shift towards a more open acknowledgement of sexual desire and erotic thoughts (Bhugra, 2008). The rates of tickets were divided into five or six grades, thereby making films more affordable for the working classes.

\section{PSYCHODYNAMICS AND CINEMA}

The psychodynamic of depression is well explained in the film House of sand and fog. Object relations theory 


\section{Psychological Outlook of Cinema}

provides a framework for an understanding of this film. In this film the child cannot tolerate the object of aggression and the object of libido being the same, and to tolerate the potential destruction of the good object, the object is split into good and bad, in order to protect the integrity of the good object. When the child experiences good enough parenting and is not rejected or retaliated against by the parent, the child begins to take responsibility for his own aggression and progressively sees himself and others as whole objects. Invaders from Mars another film useful to understand the separation anxiety. The film Nine To Five portrays the Sexual harassment in this the female character struggles to prove it (Zerby, 2005).

\section{PSYCHIATRIC DISORDERS IN CINEMA}

The use of film for teaching psychiatry as movies shows vivid examples of psychopathology in life context (Rosenstock, 2003).

\section{SCHIZOPHRENIA}

The release of the film A beautiful mind (2003) has made the process much easier. The movie shows symptoms of schizophrenia and complications, and it gives viewers especially patients and families, hopes for recovery. An Angel at my table (1990) the director portraits the story of odd childhood experience, finds out she may or may not have schizophrenia, it also includes the 8 years hospitalization in a mental hospital. Angel baby (1995) the story goes like two patients of schizophrenia meet at a clinic and there they start loving each other, the woman gets pregnant, both of them go off medications after that they become symptomatic, in this film the director Michael Rymer exposed the various symptoms of schizophrenia, illness effects and the quest for social Rehabilitation. Bewitched (1945), outcaste how psychotherapy cures schizophrenia, it picture the auditory hallucination which is one of the core symptoms of schizophrenia. Bird (1984) they have illustrated beautifully the origin of psychosis, he gets hospitalized and starts identifying with birds. It also helps the audience to identify the catatonic features one of the subtypes of schizophrenia. Conspiracy Theory (1997) depicts the differencebetween Paranoid personality disorder and schizophrenia, the patient has the suspiciousness that the psychiatrist is controlling his mind this film is akin to Manchurian candidate (Weddding, 2005).Family Life (1971) portrait a 19-year-old British female develops schizophrenia and how she cognitively deteriorates. It also explains about the poor compliance, due to expressed emotion by the parents and stigma from the society. Invasion of the Body Snatchers (1956) in this film Capgras syndrome was shown excellently. The Saint of Fort Washington (1993) a youth with schizophrenia becomes homeless, he turns towards his peer group for support it also portraits the realistic look at social issues in schizophrenia (Gabbard, and Gabbard, 1987). The recent most movies relating psychiatry is Shutter Island (2010) where Leonardo Dicaprio casts a schizophrenia patients the description of criminal mental asylum in Europe of the early century is beautifully given in this movie.

\section{SCHIZOAFFECTIVE DISORDER}

Shine (1996) Piano genius after attacked with schizoaffective disorder gradually he loses his piano skills and after the psychiatric treatment he recovers his talent it shows the better part of the illness.

\section{BIPOLAR DISORDER}

In $M r$. Jones, Gere accurately portrayed a highfunctioning, creative, and intellectual man with bipolar disorder. It is frequently utilized as a training tool to acquaint students and families with the disorder.

\section{BORDERLINE PERSONALITY DISORDER}

In the film fatal attraction, Alex forest was a borderline personality disorder, in that they have depicted the various borderline features like unstable mood, self -destructive behaviour etc. 


\section{Psychological Outlook of Cinema}

\section{OBSESSIVE COMPULSIVE DISORDER}

Schwartz (2002), sites As Good As It Gets' character, Melvin Udall, as an illustration of the classic symptoms of Obsessive-Compulsive Disorder (OCD). In the film Aviator Leonardo plays the role of obsessive compulsive disorder.

\section{SUBSTANCE USE DISORDER}

A Man Loves A Woman, this film can be used for teaching about substance use disorders (AMSP, 2007).

\section{PSYCHOTHERAPY IN CINEMA}

Wedding and Boy (2006) cites the film A League of Their Own, serves as an entertaining case study that embraces the concept of early family contracts and their influences throughout life. This film can be used to provide psycho-education about alcoholism, through the character of Jimmy Dugan, a leading baseball star whose career is lost because of alcoholism.

\section{TYPES OF THERAPEUTIC CONTACT USED IN FILMS}

The five types of therapeutic relationship identified by Clarkson (1997) are useful in describing the client/therapist relationship in therapy as depicted in the film.

The first type is the working alliances it is mutual cooperation between the client and the therapist, in the film Silent fall, Richard Dreyfuss portrays a therapist work with an autistic child to decipher, the murder of his mother. He discovers that through repetitive games, such as opening and shutting the kitchen cabinet doors and drawers together they can join in a mutual task. The second type, the Unfinished relationship, parallels the analytical concept of transference. In this type the therapist become the tool to engage the person more fully in authentic contact with self and others. In the film ordinary people Judd hirsch as Dr, Berger works with his client to unravel the memories of a traumatic boating accident in which the clients brother dies. The third style is the reparative relationship can be understood as a corrective experience or giving the patient what was needed in the moment in the film one flew over the cuckoos nest jack nicholson portrays the patient mumurphy, who provides corrective experience with the young demasculinized patient billy bibbit, an Indian chief and even develop a basket ball team. The final style is the transpersonal relationship is a spiritual dimension of being together and of presence in the healing process. In the film troy in the star trek it as been depicted.

\section{INDIAN CINEMA}

Bhugra (2008) cites the case of Hum Kisise Kam Nahin, The hero Sanjay Dutt, is a patient suffering from paranoia. The actor Amitabh Bachchan plays the role of a psychiatrist, wears a white coat and uses a stethoscope. He confirms the diagnosis of anxiety by simply checking the pulse using a stethoscope with the perception given to the audience that all mental illnesses are like physical illness. Also in the film Rakhwala, in which Shabana Azmi plays the role of a mentally retarded woman. It would be perceived by the audience as mental illness as the viewer may not be able to differentiate between different mental illnesess. Baharon ki manzil is the story of a young woman who recognizes her husband as her brother in law, subsequently she becomes more suspicious, she discovers a body in her wardrobe, although when she gets others to see it the body has disappeared. The psychiatrist starts to believe in her and has an EEG machine, which helps him make the diagnosis, notwithstanding the fact that EEG is used to diagnose epilepsy primarily and, although epilepsy and mental illness are associated, one cannot diagnose mental illness from EEG alone. In the film Karorpati, Kishan behaves like a child, as if he has a low IQ. The uncle decides that he should be sent to a lunatic asylum. Himmat's observations on mad people include, who shouldn't be afraid of mad people, these people are very wise in some ways. Kishan falls and hurts himself, as a result of which he recovers from his madness. The doctor pronounces 


\section{Psychological Outlook of Cinema}

him cured of his madness and emphasizes that this sort of recovery is quite common. Similarly in the film pagla kahin $\mathrm{ka}$, the film tries to raise the topic of madness that is hereditary and precipitated by stress, death, loss, bereavement. However, the personality of the patient is abnormal and portrayed comically. To conclude we have looked at only a small number of films, among these, the common themes of madness are varying, it is often the hero who is ill and the heroine is the carer. Madness is used as comedy and villainy and as an excuse to demonstrate the suffering which is caused by loss of stress, and yet can be easily cured by believing in the mad individual and through love rather than medication. In the recent years there are few standard movies based on psychiatric disorders. In the film Anniyan (Tamil) Aparachit (Hindi) depicted the lead actor Vikram to have Dissociative Identity Disorder, another movie which also shows Dissociative Identity Disorder is Chandramukhi (Tamil), Bhool bhulaiyaa (Hindi) casted by Jotika. Karthick calling karthick states the lead actor to have been suffering from schizophrenia. This movie like psycho (1960) creates confusion among the audience whether the lead actor actually has schizophrenia or dissociation. Movies like Taare zameen par based on dyslexia, My name is khan based on Aspergers syndrome help the viewers to have some knowledge about childhood developmental disorders. In the movie Once upon a time in Mumbai, beautifully describes how conduct disorders leading to a Dissocial personality disorder.

\section{CINEMA : GOOD AND BAD EFFECTS}

Psychological effects of films include influencing fashions, dress, jewellery, hair styles, personal mannerisms, and speech. It also influences antisocial behaviour, crimes and delinquency. Mudur (2005) explains that, in the film Bunty Aur Babbli Amitabh Bachan as the passion of smoking Bidis this motivates the youth and other individuals who view the hero as their role model, but the way the hero is depicted in the movie, makes an attraction towards the smoking habit, it gives the youth the craving just to try it ones, the film basically revolves about an police officer, and it gives an false image that the police officer can smoke.

\section{ECT AND CINEMA}

In the film Raat aur Din, when the psychiatrists see that her violence is increasing, he decides to give ECT. There is no consent is taken from patient or the guardian. The delivery of the ECT is very dramatic, she is tied down, a mouth gag is inserted, and a nurse presses the button. Her scream is heard outside, inspite of her mouth gag. The image of ECT in Hindi films is extreme. It is seen as punitive and is used as dramatic device to highlight the cruelty of the modern psychiatry (Bhugra, 2008).

\section{HYPNOSIS IN FILMS}

Even though Freud abandoned hypnosis as a means of accessing the unconscious in 1909. Films such as The magician (1926), Under the hypnotists influence (1897), Cabinet of Dr Caligari (1919). Hypnosis is probably the most misrepresented of all psychiatric treatments on film. Movie seldom as used hypnosis for good, most of the time it portraits, that it has evil, helping a person to attempt a suicide (Byrne, 2009)

\section{PATIENT - THERAPIST RELATIONSHIP}

Atkinson (1997) Unethical relationships have been depicted in films of every genre; for example with male psychiatrists in Carefree (1938), Tender is the Night (1961) and Ltlith (1964); and female psychiatrists in Spellbound (1945),They Might be Giants (1971), The Man who Loved Women (1983) and Mr Jones (1994).

\section{STIGMA}

Generally media as depicted mental illness in an negative manner, but the fact is that it as potential role to play with the society, in order to reduce the stigmatization of the community, a film I am still here, about schizophrenia, were shown to 163 people and after the film the individuals attitude towards severe mental illness changed to positive, but still they have 


\section{Psychological Outlook of Cinema}

the stereotype that they are violent, dangerous, but they are interactable (Penn, 2003).

\section{ROLE PLAY}

A selected clip from the movie, When A Man Loves A Woman can be used to set up a role play to improve patient competency in the area of alcoholism.

\section{PSYCHOANALYSIS AND THE CINEMA}

Khamoshi is probably the first Hindi film to describe the descriptive aspect of psychoanalysis. In this film the chief psychiatrist explains about Freudian analytical thinking, The daughter develops feelings for the father and the son for the mother, which are called Electra and Oedipal. Once it is realized that these feelings are not acceptable socially, the boy starts searching for the mother in different faces. He falls in love with the face in which he finds this trust. If this trust is broken, the mental suspicion comes to the fore. Arun Choudhury has come to us in such a condition. You will have to act in such a way that his attraction for his mother and lover becomes the same. This is called establishing the rapport with the patient, so that lost trust is regained. This was how dev was treated and this is how you will treat Arun chaudhury. Dev's mother invites her to visit their house and acknowledges, after Radha has touched her feet to greet her, I gave him birth, but you have given him new life, thereby emphasizing the maternal/fraternal nature of Radha's relationship with dev. Furthermore, this hint of the oedipal complex and the way mother-son relationships work is an interesting paradox (Bhugra, 2003).

The comparisons between Raat aur Din and the three faces of eve are inevitable. In the later one psychiatrists uses hypnosis to bring eve black and eve white together. When the psychiatrist begins to use hypnosis, a third personality, jane, emerges as the integration of the two selves. In Raat aur Din there are only two selves: peggy and baruna, differentiated by their clothes, drinking and smoking habits, establishing a clear distinction between the west or Christian and the east or Indian, worlds (Bhugra and De Silva, 2007).

\section{CINEMA, PSYCHOLOGY IN CIP}

In CIP there is also an academic program called movie club, in that a movie is shown after that discussion occurs in the context of diagnosis, psychodynamics, defence mechanisms, psychotherapy etc. in the recent years we had discussion on the movie Reader, Fatal attraction and Perfume. Further the patient is also shown movie on Saturdays as their part of the treatment.

\section{FUTURE DIRECTION}

More films should come on special population like autism, mental retardation etc. And the film should portray the exact features of the mental illness not to under or over exaggeration of the symptoms. Cinema should focus to reduce the stigma on mental illness and also create awareness regarding the early intervention and the availability of various treatments.

\section{CONCLUSION}

Cinema being an audio-visual medium has got an immense power to influence the society through people who watch it; it is not the technology which contaminates or glorifies culture and values in the society but the people who use it, by knowing or not knowing its good or bad effects. Movies combine realism with imagination and compress lots of information, fun and entertainment into a limited time period (Hesley and Hesley, 2001). Although it should be emphasized that the cinema may tend to over/under exaggerate the symptoms and behaviours experienced by many individuals with the disorders, many movies depicts a textbook example of the disorder(s) and are valuable for teaching (Goldberg, 2005). The image projected in the cinema, allow the people to look what's happening in the family of the projected cinema, it gives solution to the individual problem, it confirms an individual view and also his prejudices, it is also 


\section{Psychological Outlook of Cinema}

a medium of fun and entertainment, it also mirrors the society by what is going on (Anneau, 1968). It is also a medium for communicating cultural and social values, and thus as a tool for bringing about a better social order (Murthy, 1980).

\section{REFERENCES}

Anneau, M.W. (1968). The use of entertainment films in psychiatry and mental health lecture sessions. In Proceedings of the 20th World Congress. Washington: World Federation for Mental Health.

Atkinson, J.A. (1997). The psychiatrist, the patient, their relationship and the movies, Psychiatric Bulletin, 21, 369-370.

Berg-Cross, L., Jennings, P. \& Baruch, R. (1990). Cinematherapy: Theory and application. Psychotherapy in Private Practice $8(1), 135-156$.

Bhugra, D. (2003). Teaching psychiatry cinema, Psychiatric Bulletin (2003), 27, 429-430

Bhugra, D. (2006).Mad Tales from Bollywood: Portrayal of Mental illness in Conventional Hindi Cinema. New York: Psychology Press.

Bhugra, D. (2008). Mad tales from Bollywood: Portrayal of mental illness in conventional Hindi cinema, psychology press, Newyork.

Bhugra, D. and De Silva, P. (2007). The silver screen, printed page and cultural competence, The psychologist 20,9.

Bordwell, D. \& Carroll, N. (eds.), Post-Theory. Reconstructing Film Studies,Madison: University of Wisconsin Press, pp. 87-107.

Bordwell, D. \& Thompson, K.(1993). Film Art - An Introduction. New York: McGraw-Hill. In P. Persson. (2003).Understanding cinema : A psychological theory of moving imagery. Cambridge, UK : Cambridge University Press.

Bordwell, D. (1996). "Convention, Construction, and Cinematic Vision,"In

Byrne, P. (2009) Psychiatry in the movies, British journal of psychiatry, 194-196.

Calisch, A. (2001). From reel to real : Use of video as a therapeutic tool. Afterimage, 29(3), 22.

Clarkson, P. (1997). Variation on I and thou. Gestalt review, 1 : 56-70.

Dermer, S.B. \& Hutchings, J.B. (2000). Utilizing movies in family therapy: Applications for individuals, couples, and families. The American Journal of Family Therapy, 28, 163-180.

Evans, A. (2001). The Virtual Life, Escapism and Simulation in our media world. New York : Fusion Press.

Fox, G. (2003). Teaching Normal Development Using Stimulus Videotapes in Psychiatric Education, Academic Psychiatry, $27: 4$.

Gabbard, K. and Gabbard, G.O. (1987). Psychiatry and the cinema. Chicago, The university of Chicago press.
Goldberg, (2007). Beneficial film guides, Turn Box Office Movies Into Mental Health Opportunities : A Literature Review and Resource Guide for Clinicians and Educators

Graesser, Arthur, Singer, Murray \& Trabasso, T. (1994). "Constructing InferencesDuring Narrative Text Comprehension," Psychological Review. Vol. 101, No. 3,371-95. In P. Persson. (2003). Understanding cinema : A psychological theory of moving imagery. Cambridge,UK: Cambridge University Press.

Gross and Levenson (1995). Emotion elicitation using films, cognition and emotion, 9, 87-108.

Hesley, J.W. and Hesley, J.G. (2001). Rent two films and let's talk in the morning, 2nd ed., New York : Wiley.

Hesley, J. (2000). Reel therapy: movies are the hot new prescription. Psychology Today, 33 (1), 54-57.

Heston, M.L. \& Kottman, T. (1997). Movies as metaphors : A counseling intervention. Journal of Humanistic Education and Development, 36, 92-99.

Hoffman, D. (1998). Visual Intelligence : How We Create What We See. New York :

In P.Persson. (2003). Understanding cinema : A psychological theory of moving imagery. Cambridge, UK : Cambridge University Press.

Mudur, G. (2005). Indian government bans smoking in new films and TV serials, BMJ, 33025.

Murthy, N.V.K (1980). Cinema and society. Bangalore, India: Bangalore University.

Newton, A.K. (1995). Silver screens and silver linings : using theatre to explorefeelings and issues. Gifted Child Today, 18, $14-19,43$.

Norton. In P. Persson. (2003). Understanding cinema : A psychological theory of moving imagery. Cambridge, UK : Cambridge University Press.

Penn, D.L. Cliff, Chamberlin and Mueser, K.T. (2003). The Effects of a Documentary Film About Schizophrenia on Psychiatric Stigma, Schizophrenia Bulletin, 29(2) : 383-391.

Persson, P. (2003). Understanding cinema : A psychological theory of moving imagery. Cambridge,UK : Cambridge University Press.

Portadin, M. A. (2006) The use of popular film in psychotherapy: Is there a "cinematherapy"? Psy. D. dissertation, Massachusetts School of Professional Psychology, United States.

Reid, W.H. (2003). Terrorism and forensic psychiatry, journal of American acadameic psychiatry law, 31; 285-8.

Robinson, D.J. (2003). Reel Psychiatry : Movie Portrayals of Psychiatric Conditions, Rapid Psychler press.

Rosenstock (2003). Beyond A Beautiful Mind : Film Choices for Teaching Schizophrenia Academic Psychiatry, $27: 2$.

Schneider (1987). The psychiatrist in the movies: the first fifty years in psychoanalytic study of literature, analytical press.

Sharp, C., Smith, J.V. \& Cole, A. (2002). Cinematherapy : Metaphorically promoting therapeutic change. Counseling Psychology Quarterly, 15 (3), 269-276. 


\section{Psychological Outlook of Cinema}

Smith, M. (1995). Engaging Characters, Fiction, Emotion, and the Cinema. Oxford : Clarendon. In P. Persson. (2003). Understanding cinema : A psychological theory of moving imagery. Cambridge, UK : Cambridge University Press.

Solomon, G. (1995). The motion picture prescription : Watch this movie and call me in the morning. CA : Aslan Publishing.

Suarez, E.C. (2003). A princess in God's eyes : Cinematherapy as an adjunctive tool. Journal of Psychology and Christianity, 22(3), 259-261.

Van Dijk, T.A. \& Kintsch, W. (1983). Strategies of Discourse Comprehension. New

Wedding, D. and Boyd, M (2006). Movies and mental illness: Using film to understand psychotherapy Primary care companion journal of clinical psychiatry 8,3

York: Academic. In P. Persson. (2003). Understanding cinema : A psychological theory of moving imagery. Cambridge, UK : Cambridge University Press.

Zerby, S.A. (2005) Using the Science Fiction Film Invaders From Mars in a Child Psychiatry Seminar, Academic Psychiatry, $29: 316-321$.

\section{WEBSITE REFERENCES}

Roy, S. (2009). Reflections in Psychology : The Psychology of Entertainment accessed from URL : http : / / ezinear-ticles. com $/$ ? The-Psychology-of-Entertain-ment\&id $=4586950$ Retrieved on 10.9.2010.

www.oxforddictionaries.com accessed from URL : http :/ / www. oxfordd-ictionaries.com/definition/cinema? view=uk on 5.9.2010

www.encarta.msn.com. accessed from URL : http : //encarta. msn.com/dictionary_/cinema.html Retrieved on 5.9.2010.

www.ifsstech.wordpress.com accessed from URL : http : // ifsstech.word-press.com/2009/09/05/a-definition-ofcinema / Retrieved on 7.9.2010

Microsoft Encarta Encyclopedia (2001) History of Cinema (Software version). USA : Microsoft Corporation.

Tim, D. (2010). Main Film Genres. USA : American Movie Classics Company LLC. accessed from URL : http :/ / www.film-site. org/genres.html Retrieved on 30.8.2010 